\title{
Lessons from the Response to the Virginia Tech Shootings
}

\author{
John H. Armstrong, MD, FACS, and Eric R. Frykberg, MD, FACS
}

$\mathrm{T}$ he article by Kaplowitz et al in this special issue of Disaster Medicine and Public Health Preparedness describes the trauma system response to the wanton suicide shooting at Virginia Tech in April 2007. ${ }^{1}$ The authors are to be congratulated for sharing their experience so quickly, within just 3 months of the event (as of this writing), and in a manner that is consistent with the science of mass casualty management. The Virginia Tech shooting represents an act of domestic terrorism that generated a limited mass casualty event, as defined by Stein from Israeli experience with suicide bombings. ${ }^{2}$ Limited mass casualty events are characterized by casualties exceeding the resources required for individualized patient care for a limited time (measured in hours), an event in a limited space, and a return of the health care delivery system to normal operations on the same day. Clearly, the confined nature of the Virginia Tech event facilitated data collection and analysis.

The findings are consistent with the literature from other intentional limited mass casualty events. ${ }^{3}$ Deaths at the scene (33) outnumbered the injured (26). The first casualties to arrive were the so-called walking wounded via public transportation, not emergency medical services. Seventeen of the 26 casualties were taken to the closest hospital, exemplifying the geographic effect. The Injury Severity Score (ISS) defines the anatomic extent of injuries relative to severity. ${ }^{4} \mathrm{Six}$ body regions are scored 1 to 6 (minor to unsurvivable), based on the Abbreviated Injury Scale, and the top 3 scores are squared individually and summed collectively. The ISS ranges from 1 to 75 , with mortality increasing at ISS $>15$. Thus, the percentage of casualties within a population with ISS $>15$ defines the critically injured population and is the focus of triage efforts. Typically, 20\% of any given casualty population is critically injured; at Virginia Tech, this number was $19 \%$. The overall mortality of those who survive at a disaster scene is initially low, and at Virginia Tech was 3.8\%. However, the more relevant statistic is the mortality rate of the critically injured, ${ }^{5}$ which in the Virginia Tech response was $20 \%$. Comparison should be made with the literature on limited mass casualty events, which has lower critical mortality rates than larger mass casualty events.

Field triage was completed within 53 minutes of the second shooting event. Triage accuracy is essential to identify the
$20 \%$ who are critically injured. ${ }^{5}$ Undertriage misidentifies the critically injured as noncritically injured, and overtriage dilutes the critically injured population with noncritically injured, making it more difficult to identify the critically injured. The undertriage rate at Virginia Tech was 10\% (1 of 10 ), with a correspondingly higher overtriage rate of $69 \%$ (11 of 16). The documented geographic effect in this incident was the likely reason for this substantial overtriage rate. It would be interesting to look at another dimension of overtriage by knowing the operations that were performed on the $38 \%$ of casualties taken to the operating room. There is a tendency to overtriage casualties to the operating room, with a usual, nonmass casualty mindset that leads to rapid depletion of resources.

Why is triage accuracy so important? Because under- and overtriage increase the critical mortality rate. The $69 \%$ overtriage rate at Virginia Tech corresponds to the critically injured mortality rate of $20 \%$, based on the graphic distribution of overtriage to critical mortality rates in 10 terrorist bombing incidents. ${ }^{5}$ Overtriage is not the solution to finding people who are critically injured, as demonstrated by Hirshberg and colleagues in a dynamic computer modeling exercise; overtriage overloads a hospital and effectively reduces the hospital's surge capacity. ${ }^{6}$ Recognizing that triage errors will occur even with the most experienced triage officers in the chaotic atmosphere of these events, ${ }^{7}$ what is the solution to triage inaccuracy that accounts for human error in chaos? The creation of error-tolerant systems that reduce error sequentially through multiple levels of triage as casualties move from the event through prehospital, hospital, and redistribution phases.

This report from rural America is significant for several key reasons: it reemphasizes that no part of the United States is immune to mass casualty events and illustrates that an effective regional trauma system readily serves as the framework for effective mass casualty management. The planning and regional organization in southwestern Virginia did allow a rapid and organized response to deliver patients quickly for care, even if they were overtriaged. One of the reasons that the event generated a limited, as opposed to a full, mass casualty response was the ready availability of a network of hospitals to include a level I trauma center. How many other 
areas of the country can demonstrate the level of preparedness shown by the medical response to the Virginia Tech shooting?

Trauma center designation is a sign of mass casualty preparedness; level III centers are relevant, particularly in rural settings. They have the ability to provide initial evaluation and management of casualties and connectivity to the regional trauma system through existing transfer agreements. ${ }^{8}$ These agreements worked well during the Virginia Tech shooting, with transfer from local level III to regional level I centers. It appears that the Health Resources and Services Administration funds that enabled the establishment of a regional health system model were well spent.

The after-action report emphasized the need for broad communications in casualty tracking, as well as better communication linkages between the university and community health care services. It would be interesting to know what individual, organizational, community, and regional disaster training was in place in Blacksburg and southwestern Virginia, as well as the nature and frequency of community mass casualty drills. Furthermore, it would be fruitful to compare the regional hospital coordinating plan with the actual process that occurred and to report on the specific changes to this plan. Only when identified lessons are incorporated into plans and then practiced do they become lessons learned.

What lessons do the response to the Virginia Tech shooting teach other communities? The first lesson is supporting trauma system development promotes public health preparedness for mass casualty incidents. Second, community risk assessment should identify hazards for large organizational populations, such as universities, and incorporate these populations in the plan. Third, proactive mass media management must occur by leveraging existing media relationships and establishing crisis media engagement. Fourth, beware the second-hit phenomenon, whereby the mechanism of the first event remains in play or generates second mechanisms for further events. In the case of the Virginia Tech shootings, the first event in the dormitory resulting in 2 fatalities was followed by a larger event in the classroom building, both using the same mechanism. Security must happen early at receiving hospitals to prevent expansion of the event through second hits.
We offer several cautions: First, a natural reaction to a campus shooting is to focus planning on preventing such a specific event. It is important to perform all-hazards planning, whereby the plan can be tailored to specific events, rather than having specific events dictate the plan. Second, the event, time-limited for physical casualties, remains quite real within the community, the State of Virginia, and the nation, at 3 months and into the future. How psychosocial needs are addressed will determine the ultimate healing from the event.

\section{About the Authors}

Dr Armstrong is Assistant Professor of Acute Care Surgery, and Dr Frykberg is Chief of the Division of General Surgery, University of Florida.

Correspondence and reprint requests to Dr John H. Armstrong, 1600 SW Archer Rd, Box 100286, Gainesville, FL 32610-0286 (email: john.armstrong@ surgery.ufl.edu).

Received for publication July 8, 2007; accepted July 12, 2007.

ISSN: 1935-7893 @ 2007 by the American Medical Association and Lippincott Williams \& Wilkins.

\section{DOI: 10.1097/DMP.0b013e3181514969}

\section{REFERENCES}

1. Kaplowitz L, Reece M, Henry Hershey J, Gilbert CM, Subbarao I. Regional health system response to the Virginia Tech mass casualty incident. Disaster Med Public Health Preparedness. 2007;1 (Suppl 1):X-X .

2. Stein M. Urban bombing: a trauma surgeon's perspective. Scand J Surg. 2005;94: 286-292.

3. Auf der Heide E. The importance of evidence-based disaster planning. Ann Emerg Med. 2006;47:34-49.

4. Baker SP, O'Neill B, Haddon W Jr, Long WB. The injury severity score: a method for describing patients with multiple injuries and evaluating emergency care. J Trauma. 1974;14:187-196.

5. Frykberg ER. Medical management of disasters and mass casualties from terrorist bombings: how can we cope? J Trauma. 2002;53:201-212.

6. Hirshberg A, Scott BG, Granchi T, Wall MJ Jr, Mattox KL, Stein M. How does casualty load affect trauma care in urban bombing incidents? A quantitative analysis. J Trauma. 2005;58:686-695.

7. Ashkenazi I, Kessel B, Khashan T, et al. Precision of in-hospital triage in mass-casualty incidents after terror attacks. Prehosp Disaster Med. 2006; 21:20-23

8. American College of Surgeons Committee on Trauma. Resources for the Optimal Care of the Injured Patient . 2006, pp 125-131. American College of Surgeons Web site. https://web2.facs.org/timssnet464/acspub/frontpage. cfm?product_class $=$ trauma. Accessed August 7, 2007. 